\title{
Study of Thermo-Physical Characteristics and Drying of Araucaria Wood from the City of El Jadida, Morocco
}

Nora Bouhaddour ${ }^{1, *}$, Abdelkrim Moufakkir ${ }^{1}$, Sara Belarouf $^{1}$, Abderrahim Samaouali $^{1}$, Hanane Sghiouri El Idrissi ${ }^{1}$, Abdellah Elbouzidi ${ }^{2}$, Salah El Alami ${ }^{3}$

${ }^{1}$ Team Thermodynamic-Energy, Energy center, Department of Physics, Faculty of Sciences, Mohammed V University, B.P. 1014, in Rabat, 10090, Morocco

${ }^{2}$ Laboratory of Atmospheric Physics, Materials and Modeling, Faculty of Science and Technology of Mohammedia, Hassan II University of Casablanca, Morocco

${ }^{3}$ Laboratory of Condensed Matter and Interdisciplinary Sciences, Faculty of Sciences, Mohammed V University in Rabat, 4 Avenue Ibn Battouta B.P. 1014 RP, Morocco

\begin{tabular}{l} 
A R T I C L E I N F O \\
\hline Article history: \\
Received: 04 January, 2021 \\
Accepted: 16 February, 2021 \\
Online: 17 March, 2021
\end{tabular}

Keywords:
Wood
Araucaria
Characterization
Thermophysics
Thermal conductivity
Humidity
Drying

\section{Introduction}

This type of wood called Araucaria is one of the three genera of plants in the Araucariaceae family. This type comes from its name in the region of Araucania " Arauco " in Chile where two species of this type originate. The araucaria is also called "Chilean pine ". It has been around for several years. Fossil remains indicate that during the Mesozoic period they were abundant in the southern hemisphere [1].

Araucaria tree (Figure 1.) resembling pine trees with leaves in needles or triangular scales giving them a very special appearance. It was previously very popular as a decorative tree in public or ${ }^{*}$ Corresponding Author: Nora Bouhaddour, Email: ab.moufakkir@gmail.com

\begin{abstract}
A B S T R A C T
The aim of this study is, on the one hand learn about this type of wood, and on the other hand, is to study the processes the thermophysical characterization of araucaria wood from the city of el Jadida, Morocco, and on the other hand, will study the processes related to evaporation. Wood is defined industrially as an anisotropic and heterogeneous material formed over many years of a tree's life. The anatomical study of wood generally involves the examination of three directions of reference, the axial, radial and tangential directions. And a study of the constituent elements of wood being oriented in several directions, it follows from experience that its thermal properties differ in the longitudinal, radial or tangential direction, where thermophysical tests are carried out at wood moisture contents between 10 and 11\%. Concerning the thermal properties, study highlighted, the determination of thermal conductivity, specific heat, thermal diffusivity and then the thermal effusivity of araucaria wood at different temperatures: $25^{\circ} \mathrm{C}, 35^{\circ} \mathrm{C}, 50^{\circ} \mathrm{C}$ and $60^{\circ} \mathrm{C}$. The results are obtained experimentally by a device called "CT-Metre". He illustrated that this kind of wood is more conductive of heat in the longitudinal direction than the radial and tangential directions. Also, have determined the evaporation rate under well determined conditions, chose an enclosure to keep the set temperature, and then add $\mathrm{NaCl}$ to keep humidity at $75 \%$, which also gives important results.
\end{abstract}

private gardens in Europe. In addition, the Araucaria fir is a large tree, with a straight trunk and very spreading low branches, which can reach more than $60 \mathrm{~m}$ in height in its natural state. The diameter of the trunk will hardly exceed 1.50 meters, its average density at 12\%: $490 \mathrm{~kg} / \mathrm{m} 3$ [2, 3]. In this article have treated the thermophysical properties such as thermal conductivity, specific heat per unit of volume, thermal diffusivity, thermal effusivity, this characterization done at different temperatures $\left(25^{\circ} \mathrm{C}, 35^{\circ} \mathrm{C}, 50^{\circ} \mathrm{C}\right.$ and then $60^{\circ} \mathrm{C}$ ) and then determine humidity on the wood sample called " Araucaria ", the sample of a rectangular sizing $(79.37 \times 77.66 \times 82.10 \mathrm{~mm})$. Also determined the evaporation rate on a small piece of a rectangular sample of wood with a surface section of $(\mathrm{S}=6.25 \mathrm{~cm} 2)$ and $(\mathrm{h}=5 \mathrm{~cm})$ in height, the sample are 
first well dried in an oven at temperature $60^{\circ} \mathrm{C}$ until the weight is normalized. The impregnations are applied to bare test tubes. They are placed perpendicularly on the grid, in a tank at the bottom of which the level of distilled water is kept constant throughout the duration of the experiment. The measurements of the thermal characterization part were obtained by a CT-Metre device at the Laboratory of Thermodynamics - Energy, Energy Center, Faculty of Sciences, Mohammed V University, Rabat, Morocco. The device used allows the thermal conductivity and specific heat to be determined experimentally in accordance with standard NF EN 993-15 of 2005. In addition, in our team are interested in thermal characterization of materials: wood, concrete, ceramic, etc. [4- 11].

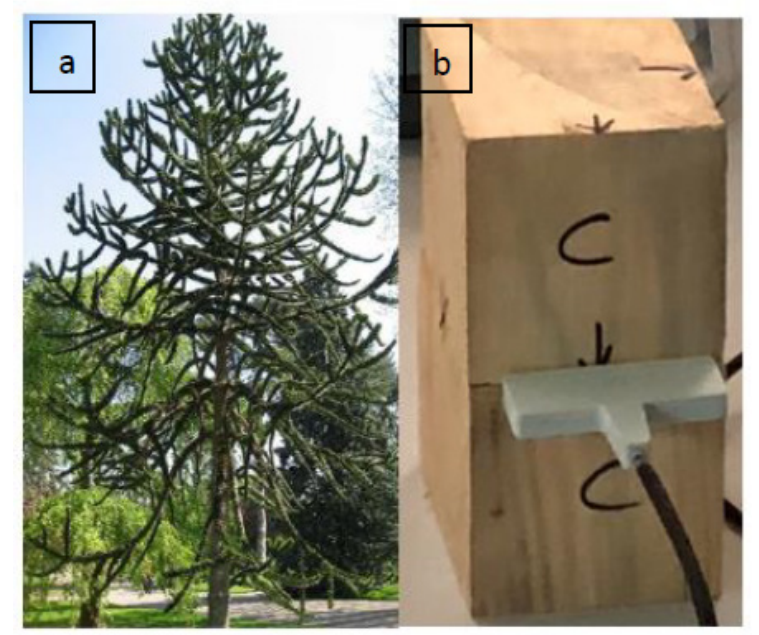

Figure 1: a) Araucaria tree, b) Araucaria samples

\section{Assembly presentation}

To measure the thermal conductivity of a material is effected by conductimeter using a device "CT-metre" linked by accessories such as probes solid materials (using ring probe) and liquids (using wire probe) In order to allow us to evaluate thermal conductivity and specific heat volume. A glove box made up of a thermocouple which is used to fix the temperature and an interface which couples the assembly with a computer in order to display and examine the digital measured values.

The CT-Metre (Figure 2.) device, easily transportable, was to make calculations in order to allow to evaluate with precision, the thermal properties of a certain number of materials, such as: powdered substances, bitumen, earth, cellular concrete, rocks, complex products or resins, brick.

The mechanical and electrical properties of the control unit:

- Power delivered for the ring probe: 0 to $2.5 \mathrm{~W}$

- Heating time: $400 \mathrm{~s}$

- Measure time: $500 \mathrm{~s}$

- Resistance: $2.5 \mathrm{ohm}$

- Dimension of the cabinet: $400 * 145 * 260(\mathrm{~mm})$

- Weight of the box: $8 \mathrm{Kg}$

- Mains power supply: $230 \mathrm{Vac} / 50-60 \mathrm{~Hz}$
The ring probe consists of a flexible printed circuit $(0.2 \mathrm{~mm}$ thick $-60 * 90 \mathrm{~mm}$ ), which is intended to be inserted between two flat pieces of the sample to be measured (their surfaces have been corrected beforehand).

The glove box plays a role in preserving the temperature variations of a sample in our case the wood sample (Araucaria), the latter composed of three materials linked to each other and each giving their function is the following: a contact thermometer which regulates the requested temperature, burning light bulbs during launching of the sample in the glove box to heat the sample then a fan which stirs the heat in the box.

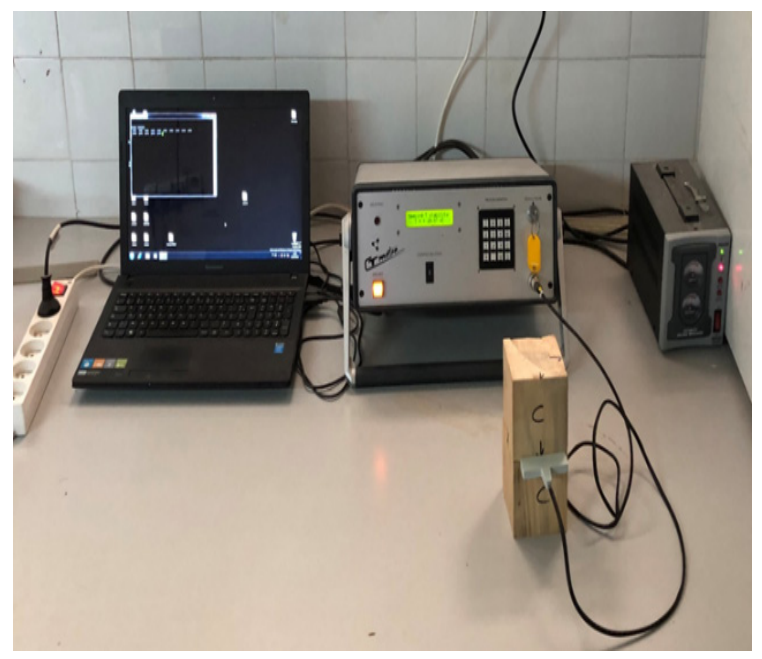

Figure 2: Launch of Araucaria samples in CT-Metre device

\section{Development of the experiment and drying kinetics}

When the samples are at their saturated porosity, the evaporation experiments are carried out at the end of the capillarity experiment. They are packaged in neoprene bags so as to leave the upper face in contact with the ambient environment. The seal is reinforced with Teflon tape. These test specimens are placed to dry in a hermetically sealed enclosure: they are rectangular parallelepiped, with dimensions of $30 \mathrm{~cm}$ high, $40 \mathrm{~cm}$ long and 35 $\mathrm{cm}$ wide. Inside, a double cover located $5 \mathrm{~cm}$ from the bottom, limits the upset of the medium during openings, which is necessary for the weighing of the test pieces (Figure 3).

The experiment is applied in an enclosure whose air is conditioned where the temperature is kept constant is 22 , and in which a brine maintains the medium at a constant relative humidity. In our experiment chose the $\mathrm{NaCl}$ salt which gives a relative humidity of $75 \%$ under the conditions of our experience. Scales are then run regularly until constant sample weight. The tank is hermetically closed, which makes it possible to maintain a humidity close to saturation and to cancel the superposition of evaporation phenomena.

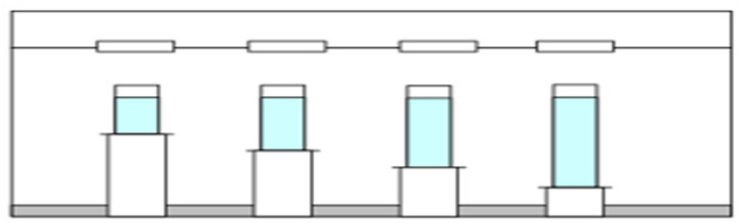

Figure 3. Diagram of an enclosure used for the drying tests 


\section{Results and interpretation}

\subsection{Thermal conductivity}

Table 1: Experimental values of thermal conductivity as a function of temperature at different temperatures of a sample of a three-sided araucaria

\begin{tabular}{|l|l|l|l|l|}
\hline Direction & $\mathbf{2 5}^{\circ} \mathbf{C}$ & $\mathbf{3 5}^{\circ} \mathbf{C}$ & $\mathbf{5 0}^{\circ} \mathbf{C}$ & $\mathbf{6 0}^{\circ} \mathbf{C}$ \\
\hline Longitudinal & 0,314 & 0,318 & 0,333 & 0,352 \\
\hline Radial & 0,219 & 0,219 & 0,227 & 0,242 \\
\hline Tangential & 0,192 & 0,196 & 0,205 & 0,229 \\
\hline
\end{tabular}

From Table 1, can plot a thermal conductivity profile by software as a function of different temperatures of a wood specimen of the genus araucaria in three directions:

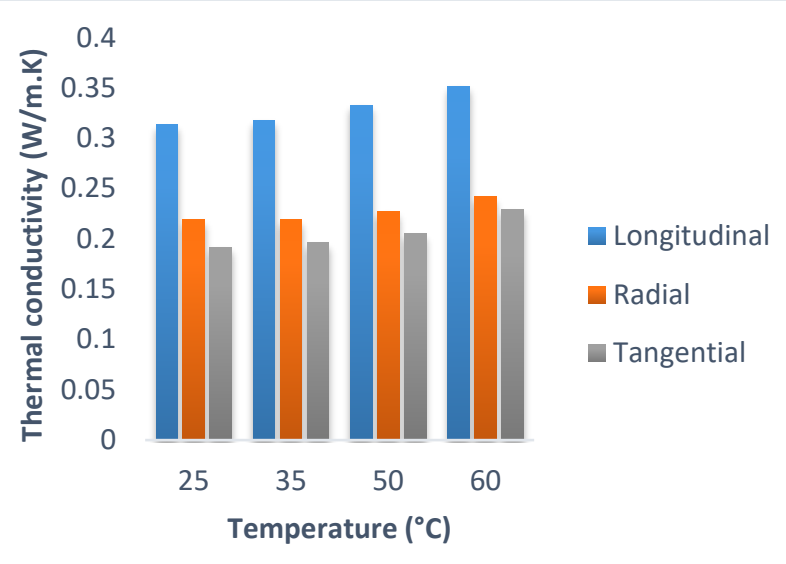

Figure 4: Thermal conductivity at different temperature for the three-way araucaria sample

Can see in Figure 4, which displays the variation of thermal conductivity according to different degrees of temperature indicating this type of wood called araucaria, that the thermal conductivity is higher on the longitudinal axis than the other radial and tangential axes hence this type of wood is a heat conductor in the axial direction (Longitudinal).

\subsection{Volume specific thermal heat}

Table 2. Experimental values of specific heat by volume $\left(\mathrm{KJ} / \mathrm{m}^{3} . \mathrm{K}\right)$ as a function of the temperature at different temperatures of the sample of three-sided Araucaria

\begin{tabular}{|c|c|c|c|c|}
\hline Direction & $\mathbf{2 5}^{\circ} \mathbf{C}$ & $\mathbf{3 5}^{\circ} \mathbf{C}$ & $\mathbf{5 0}^{\circ} \mathbf{C}$ & $\mathbf{6 0}^{\circ} \mathbf{C}$ \\
\hline Longitudinal & 1564 & 1559 & 1697 & 1767 \\
\hline Radial & 844 & 844 & 870 & 927 \\
\hline Tangential & 780 & 818 & 890 & 1113 \\
\hline
\end{tabular}

From Table 2 can plot by software a specific thermal profile for each unit volume at different temperatures of araucaria wood specimen on the three directions:

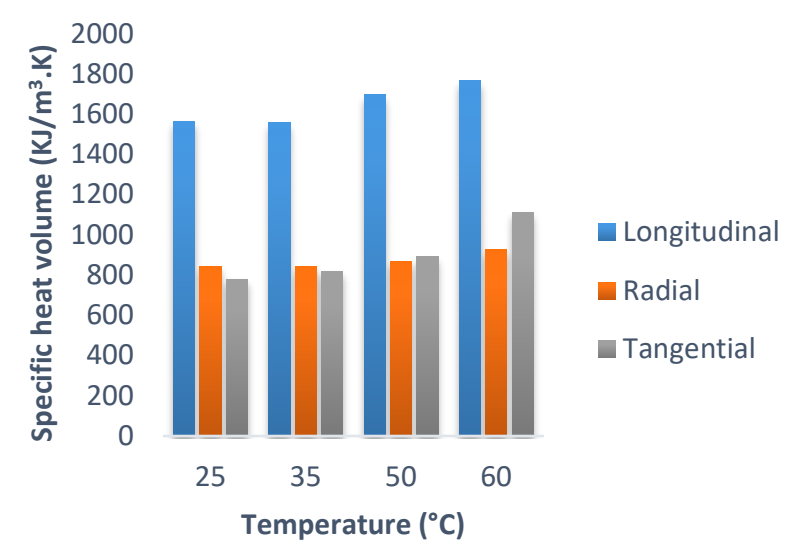

Figure 5: Experimental effect of temperature on the specific heat state of a sample of three-sided Araucaria

It can be seen from Figure 5 which presents the profile of the specific heat by volume per unit of volume at different degrees of temperature on the araucaria sample, that the a specific heat by volume per unit of volume is higher at a given temperature of 60 ${ }^{\circ} \mathrm{C}$ on the longitudinal axis of the other two radial and tangential axis, it almost degrades following the heat.

\subsection{Thermal diffusivity}

Thermal diffusivity characterizes the speed of heat propagation by conduction in a material, it depends on thermal conductivity, and the specific heat volume of a given material [13]: $\mathrm{D}=\lambda / \mathrm{C}$

With: $\mathrm{C}\left(\mathrm{J} / \mathrm{K} \cdot \mathrm{m}^{3}\right)$, the following semi-experimental values of thermal diffusion $\mathrm{D}\left(\mathrm{m}^{2} / \mathrm{s}\right)$ are thus obtained.

Table 3: The experimental values of thermal diffusivity as a function of temperature at different temperatures of a sample of three-sided Araucaria

\begin{tabular}{|c|c|c|c|c|}
\hline Direction & $\mathbf{2 5}^{\circ} \mathbf{C}$ & $\mathbf{3 5}^{\circ} \mathbf{C}$ & $\mathbf{5 0}^{\circ} \mathbf{C}$ & $\mathbf{6 0}^{\circ} \mathbf{C}$ \\
\hline & & & & \\
Longitudinal & $2,00 \mathrm{E}-07$ & $2,03 \mathrm{E}-07$ & $1,96 \mathrm{E}-07$ & $1,99 \mathrm{E}-07$ \\
\hline Radial & $2,59 \mathrm{E}-07$ & $2,59 \mathrm{E}-07$ & $2,61 \mathrm{E}-07$ & $2,62 \mathrm{E}-07$ \\
\hline & & & & \\
Tangential & $2,46 \mathrm{E}-07$ & $2,39 \mathrm{E}-07$ & $2,30 \mathrm{E}-07$ & $2,05 \mathrm{E}-07$ \\
\hline
\end{tabular}

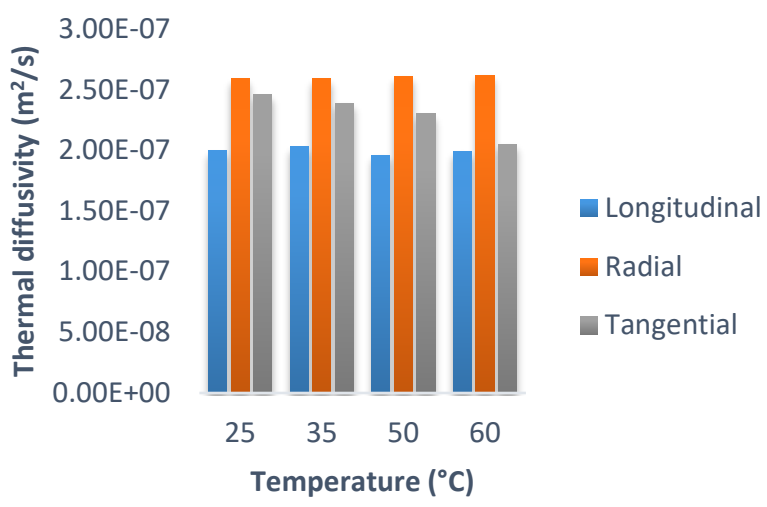

Figure 6: Thermal diffusivity at different temperature in the case of Araucaria sample on three faces 
From Table 3, can use software to plot the variation in thermal diffusivity at different temperatures for the araucaria wood sample on the three axes:

It can be seen from Figure 6 which shows the thermal diffusivity according to different temperature bottoming out $\left(25^{\circ} \mathrm{C}, 35^{\circ} \mathrm{C}, 50^{\circ} \mathrm{C}\right.$ and $\left.60^{\circ} \mathrm{C}\right)$ applied to the sample of araucaria wood, it is observed that thermal diffusivity is higher on the radial axis than the other two tangential and longitudinal axis.

\subsection{Thermal effusivity}

The thermal effusivity of a material characterizes its ability to exchange thermal energy with its environment. It is expressed by the following relation [14-17]: $E\left(\mathrm{~J} / \mathrm{m}^{2} \cdot \mathrm{K} \cdot \mathrm{s}^{1 / 2}\right)=\sqrt{\lambda \rho \mathrm{c}}$

From this relation obtain the following semi-empirical values for the thermal effusivity $\mathrm{E}\left(\mathrm{J} / \mathrm{m}^{2} . \mathrm{K} . \mathrm{s}^{1 / 2}\right)$ the measurements given in Table 4.

Table 4: Semi-empirical results of thermal effusivity as a function of temperature at different temperatures for three-sided Araucaria sample

\begin{tabular}{|c|c|c|c|c|}
\hline Direction & $\mathbf{2 5}^{\circ} \mathbf{C}$ & $\mathbf{3 5}^{\circ} \mathbf{C}$ & $\mathbf{5 0}^{\circ} \mathbf{C}$ & $\mathbf{6 0}^{\circ} \mathbf{C}$ \\
\hline Longitudinal & $7,01 \mathrm{E}+02$ & $7,04 \mathrm{E}+02$ & $7,38 \mathrm{E}+02$ & $7,89 \mathrm{E}+02$ \\
\hline Radial & $4,30 \mathrm{E}+02$ & $4,35 \mathrm{E}+02$ & $4,49 \mathrm{E}+02$ & $4,84 \mathrm{E}+02$ \\
\hline & & & & \\
Tangential & $3,87 \mathrm{E}+02$ & $4,00 \mathrm{E}+02$ & $4,14 \mathrm{E}+02$ & $4,57 \mathrm{E}+02$ \\
\hline
\end{tabular}

From Table 4, can use software to plot the variation in thermal effusivity at different temperatures for the araucaria wood sample in the three directions.

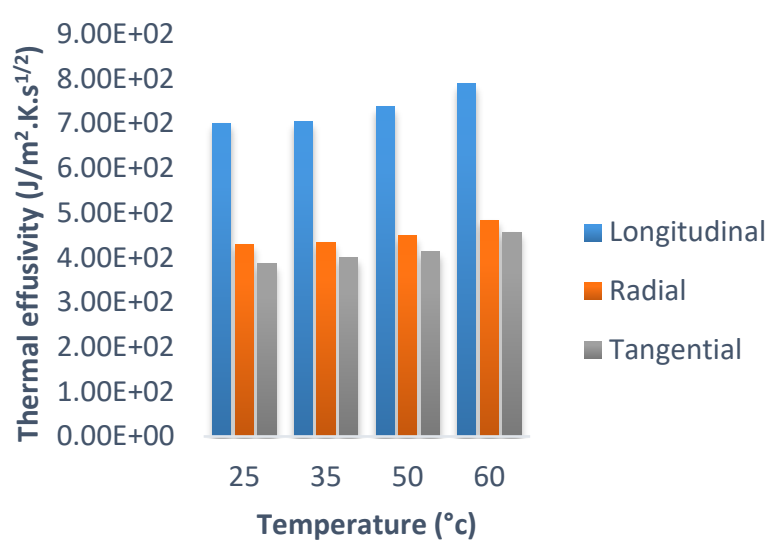

Figure 7: Thermal effusivity at different temperature in the case of a three-sided Araucaria sample

It can be seen from Figure 7, shows the thermal effusivity on the temperature according to different degrees of temperature, for the wood of araucaria, that the thermal effusivity increases on the longitudinal axis of given temperature of $60^{\circ} \mathrm{C}$ equivalent to $7.89 \mathrm{E}$ $+02\left(\mathrm{~J} / \mathrm{m}^{2} \cdot \mathrm{K} . \mathrm{s}^{1 / 2}\right)$ than the other two radial and tangential axes.

\subsection{Humidity level}

To measure humidity be accomplished by relation (I.1), after taking steps such as weighing in an analytical balance and drying in an oven for at least 72 hours so that the mass remains stable. www.astesj.com
First measure the mass of the araucaria sample $\left(\mathrm{m}_{\mathrm{h}}\right)$. After drying, the anhydrous mass $\left(\mathrm{m}_{0}\right)$ is calculated, and the humidity or water content is expressed by the following expression:

$$
H_{u}=\frac{m_{h}-m_{0}}{m_{f}} \times 100
$$

From the numerical calculation, get the moisture content of our studied sample is given in Table 5. These samples were studied in rectangular shapes, each sample is divided into two, and then proceed to heat treatments in the 'oven at $40^{\circ} \mathrm{C}$ for 72 hours to reduce the water content.

Table 5: Humidity level of the araucaria sample

\begin{tabular}{|c|c|c|c|c|c|c|}
\hline $\begin{array}{c}\text { Mass } \\
(\mathrm{g})\end{array}$ & \multicolumn{3}{|c|}{ Dimension (mm) } & \multicolumn{2}{|c|}{ Humidity (\%) } & $\begin{array}{c}\text { Density } \\
\left(\mathrm{kg} / \mathrm{m}^{3}\right)\end{array}$ \\
\hline 320.50 & $\mathrm{R}$ & $\mathrm{L}$ & $\mathrm{T}$ & Dry & Raw & 633.399 \\
\hline & 79.37 & 77.66 & 82.10 & 10,79 & 9,73 & \\
\hline
\end{tabular}

From the measurements in Table 5 derive Figure 8:

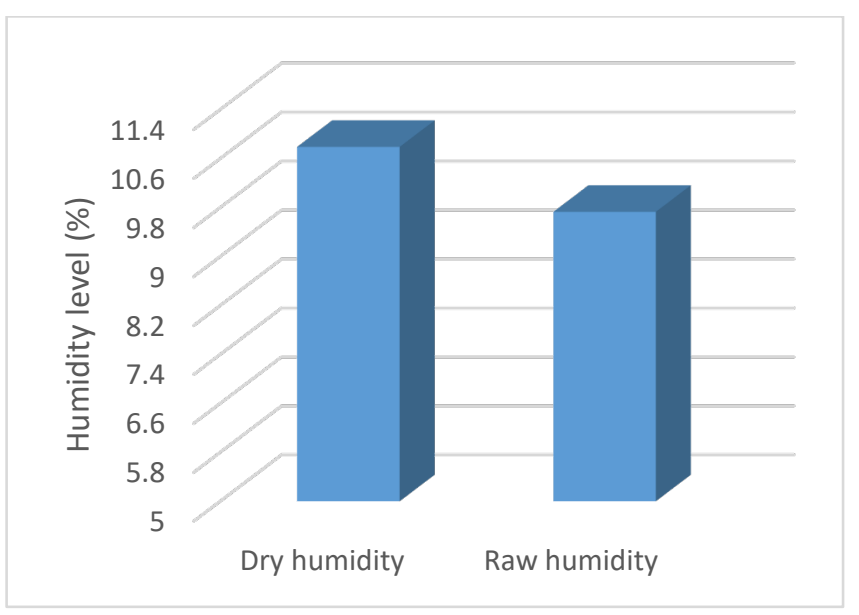

Figure 8: Humidity profile for araucaria wood

Evaporation of the araucaria sample

Table 6: Drying kinetics measured on the araucaria sample after capillary saturation under $75 \%$ relative humidity, a temperature of $22{ }^{\circ} \mathrm{C}$ and without air agitation.

\begin{tabular}{|c|c|c|c|}
\hline $\begin{array}{c}\text { Relative } \\
\text { humidity }\end{array}$ & Flux & $\begin{array}{c}\text { Critical } \\
\text { saturation }\end{array}$ & $\begin{array}{c}\text { Saturation } \\
\text { time critique }\end{array}$ \\
\hline H.R $75 \%$ & $\mathrm{~F}\left(\mathrm{~g} \cdot \mathrm{cm}^{-2} \cdot \mathrm{h}^{-1}\right)$ & $\mathrm{S}_{\mathrm{c}}(\%)$ & $\mathrm{t}_{\mathrm{Sc}}(\mathrm{h})$ \\
\hline araucaria & $-2,2.10-3$ & 76,4 & 140 \\
\hline
\end{tabular}

According to Figure 9 which shows the evaporation kinetics curve of the araucaria sample at $75 \%$ relative humidity (HR), sample 5 $\mathrm{cm}$ high and $6.25 \mathrm{~cm}^{2}$ of surface, can decompose this curve in three stages, the first stage which is linear has a constant flux $\mathrm{F}=-2.2 .10$ $3 \mathrm{~g} \cdot \mathrm{cm}^{-2} \cdot \mathrm{h}^{-1}$ and has a critical saturation time $\left(\mathrm{t}_{\mathrm{sc}}(\mathrm{h})\right) 140 \mathrm{~h}$, the critical saturation in this sample is $76.4 \%$, from the point $\mathrm{S}_{\mathrm{c}}$ beginning second stage Which is characterized by a curve not straight, by a flow decreases with time, and then the third stage its curve is linear has a very weak flow constant which vanishes over time. 


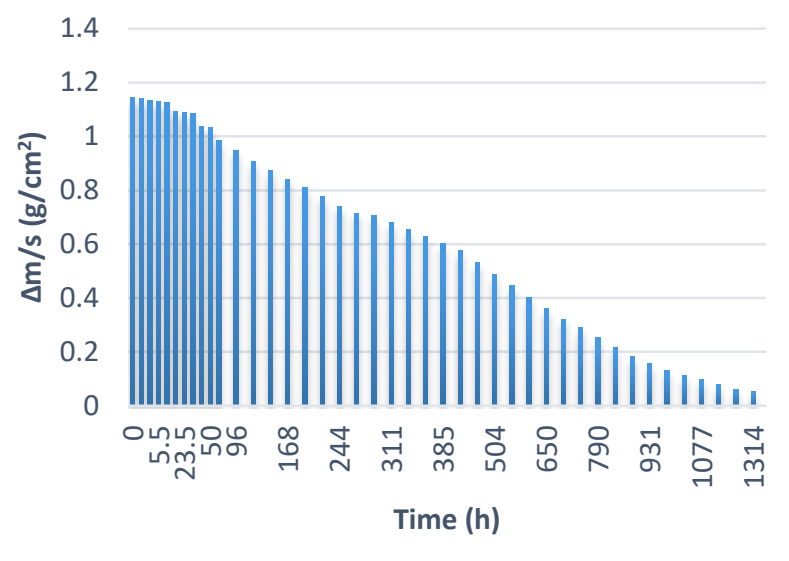

Figure 9: Evaporation kinetics curve of the araucaria sample at $75 \%$ relative humidity, test tube $5 \mathrm{~cm}$ high and $6.25 \mathrm{~cm}^{2}$ in area

\section{Conclusion}

After this thermal characterization study as well as the drying on the sample of araucaria wood from source the city of el Jadida, Morocco, conclude on the one hand that the thermal conductivity and also the specific heat per unit volume is increased at a temperature of $60^{\circ} \mathrm{C}$ on the longitudinal direction than the other two axes radial and tangential which indicates that this kind of wood is heat conductive on the axial axis (longitudinal), and on the other hand can summarize the results of wood drying in three parts, firstly, the evaporation rate $(\mathrm{F} 1)$ is stable, $\left(\mathrm{S}_{\mathrm{r}}\right)$ depends on the relative humidity, the weight loss is constant but should be negligible.

\section{Nomenclature}

H.R.: Relative humidity (\%)

F: Flux $\left(\mathrm{g} \cdot \mathrm{cm}^{-2} \cdot \mathrm{h}^{-1}\right)$

$\mathrm{S}_{\mathrm{c}}$ : Critical saturation (\%)

tsc: Critical saturation time (h)

$H_{u}$ : Humidity expressed in (\%)

$m_{h}$ : Mass of the wet sample $(\mathrm{Kg})$

$m_{0}$ : Mass of the sample after conservation in the oven $(\mathrm{Kg})$

$\lambda$ : Thermal conductivity of the material $\left(\mathrm{W} \mathrm{m}^{-1} \mathrm{~K}^{-1}\right)$

$\rho:$ The density of the material $\left(\mathrm{kg} \mathrm{m}^{-3}\right)$

c: The thermal mass capacity of the material $\left(\mathrm{J} \mathrm{kg}^{-1} \mathrm{~K}^{-1}\right)$

E: Thermal effusivity $\left(\mathrm{J} / \mathrm{m}^{2} \cdot \mathrm{K} \cdot \mathrm{s}^{1 / 2}\right)$

D: Thermal diffusivity $\left(\mathrm{m}^{2} / \mathrm{s}\right)$

C: Volume specific thermal heat $\left(\mathrm{J} / \mathrm{K} . \mathrm{m}^{3}\right)$

\section{Acknowledgment}

Thanks to the team Thermodynamic-Energy, Energy center, Department of Physics, Faculty of Sciences, Mohammed V University. Morocco

\section{References}

[1] J.C.F. Walker, B.G. Butterfield, T.A.G. Langrish., J.M. Harris, J.M. "Uprichard, Primary Wood Processing: Principals and Practice," Chapman and Hall, London, 121-152, 1993, doi: 10.1007/978-94-015-8110-3.

[2] R.B. Keey, T.A.G. Langrish, J.C.F. Walker, "Kiln-Drying of Lumber," Springer Series in Wood Sciences, Berlin, 326p, 2000, doi.org/10.1007/9783-642-59653-7.
[3] M. Amer, B. Kabouchi, R. Mohamed, A. Famiri, A. Fidah, S. E. Alami, A. Brahim, "Water Sorption/Desorption Kinetics and Convective Drying of Eucalyptus globulus Wood," Journal of the Korean Wood Science and Technology, 47(5), 557-566, 2019, doi:10.5658/WOOD.2019.47.5.557.

[4] A. Samaouali, Y. El Rhaffari, M. Hraita, L. Laanab, H. Oudrhiri and Y. Géraud, "Porous network structure and total porosity of rocks used in historical monument Chellah (Rabat)," Romanian Journal of Materials, 47(2), 222-229, 2017, hal-02961996.

[5] A. Moufakkir*, A. Samaouali, A. Elbouzidi, S. E. Alami, A. Dinane, "Thermophysical characterization of composite clay materials doped by the copper powder according to the temperature," Wseas Transactions on Environment and Development, 16, 324-329, 2020, doi:10.37394/232015.2020.16.34.

[6] A. Moufakkir*, A. Samaouali, A. Elbouzidi, A. Dinane and S. E. Alami, "The thermal behavior of the laminated composite material (Clay reinforced with copper fibers) on the effect of temperature and composition," JP Journal of Heat and Mass Transfer, 20(2), 189-204, 2020, doi.org/10.17654/HM020020189.

[7] A. Moufakkir*, A. Samaouali, A. Elbouzidi, S. E. Alami, A. Dinane, "The influence of the percentage of porosity on the thermal conductivity of a composite material, for example clay," Wseas Transactions on Environment and Development, 16, 566-572, 2020, doi: 10.37394/232015.2020.16.58.

[8] A. Moufakkir, A. Elbouzidi, A. Samaouali, "Curves characteristic of natural drying of five species of wood," Advanced Studies in Theoretical Physics, 13(2), 55 - 66, 2019, doi.org/10.12988/astp.2019.914.

[9] S. Belarouf, A. Samaouali, K. Gueraoui, H. Rahier, "Mechanical properties of concrete with recycled concrete aggregates," International Review of Civil Engineering, 11(6), 167-182, 2020, doi.org/10.15866/irece.v11i6.18478.

[10] A. Moufakkir, S. E. Alami, S. Belarouf, H. Soulami, A. Samaouali, B. Kabouchi, A. Famiri, "physical-mechanical characterisation and drying wood of holm-oak bush from azrou region - morocco," JP Journal of Heat and Mass Transfer, 21(1), 151-166, 2020, doi.org/10.17654/HM021010151.

[11] A. Samaouali, H. Sghiouri E. Idrissi, Y. E. Rhaffari, A. Moufakkir, S. Belarouf, H. Soulami, M. Charia, "thermal conductivity and porosity characterization of calcarenites stones used in historical buildings," JP Journal of Heat and Mass Transfer, 21(2), 237-250, 2020, doi.org/10.17654/HM021020237.

[12] S. Belarouf, A. Samaouali A. Moufakkir, K. Gueraoui, R. Hubert, "thermal behavior of concrete with recycled concrete aggregates on the effect of temperature and composition," JP Journal of Heat and Mass Transfer, 21(2), 167-182, 2020, doi.org/10.17654/HM021020167.

[13] D. Demange, P. Beauchene, M. Bejet, R. Casulleras, "Mesure simultanée de la diffusivité thermique selon les deux directions principales d'un matériau," Revue Générale de Thermique, 36(10), 755-770, 1997, doi.10.1016/S00353159(97)84836-2.

[14] X. Zhang, A. Degiovanni, "Mesure de l'effusivité thermique de matériaux solides et homogènes par une méthode de "sonde" plane," Journal de Physique III, 3(6), 1243-1265, 1993, doi. 10.1051/jp3:1993196.

[15] S. Belarouf, A. Moufakkir, A. Samaouali, H.Rahier, K. Gueraoui, "Chemical-mineralogical characterization of concrete with recycled concrete aggregates," Journal of Heat and Mass Transfer, 22(1), 35-53, 2021, doi.org/10.17654/HM022010035.

[16] X. Zhang, A. Degiovanni, "Mesure de l'effusivité thermique de matériaux solides et homogènes par une méthode de sonde plane," Journal de Physique III, 3(6), 1243-1265, 1993, doi. 10.1051/jp3:1993196.

[17] J.-C. Krapez, "Mesure de l'effusivité thermique - Méthodes photothermiques (Thermal effusivity measurement - Photothermal methods)," Référence R2959, 2016, http: //www.techniques-ingenieur.fr/basedocumentaire/mesures-analyses-th $1 /$ mesure-des grandeursthermophysiques-42544210/mesure-de-1-effusivite-thermique-r2959, [Accessed 16 September 2020]. 